\title{
A potential role of IL- 6 in the chito-oligosaccharide-mediated inhibition of adipogenesis
}

\author{
Bojlul Bahar, John V. O’Doherty and Torres Sweeney* \\ Institute of Food and Health, School of Agriculture, Food Science and Veterinary Medicine, University College Dublin, \\ Belfield, Dublin 4, Republic of Ireland
}

(Received 11 October 2010 - Revised 31 January 2011 - Accepted 11 February 2011 - First published online 18 May 2011)

\section{Abstract}

Recent studies have suggested that chito-oligosaccharides can have anti-adipogenic properties. The objectives of the present study were to evaluate the anti-adipogenic potential of four different chito-oligosaccharides (molecular weight (MW) <1000, 1000-3000, 3000-5000 and 5000-10000 Da) and to identify molecular mechanisms underlying the chito-oligosaccharide-mediated inhibition of adipogenesis. Mouse 3T3-L1 cells were allowed to differentiate in the presence of chito-oligosaccharide. At day 8 post-induction of differentiation, lipid accumulation, free glycerol release and the quantitative expression of adipogenic marker genes were evaluated. Chito-oligosaccharides had concentration- and MW-dependent inhibitory effects on lipid accumulation $(P<0 \cdot 001$ and $<0 \cdot 05$, respectively), as well as a concentration-dependent effect $(P<0 \cdot 001)$ on free glycerol release and the expression of adipogenic marker genes. The 5000-10000 Da chito-oligosaccharide was selected for subsequent molecular studies. A panel of forty-four lipid metabolic pathwayspecific genes was analysed by quantitative real-time PCR. Chito-oligosaccharide-mediated inhibition of adipogenesis was associated with the up-regulation of the $I L-6$ gene at all concentrations of chito-oligosaccharide examined and the PG-endoperoxide synthase 2 (PTGS2) gene at higher concentrations of chito-oligosaccharide. The effect of chito-oligosaccharide on gene expression was validated by measuring IL- 6 protein concentrations in the media. Finally, an IL- 6 promoter assay was developed to characterise the effect of chito-oligosaccharide on the transcriptional activity of the $I L-6$ promoter, which was increased in a concentration-dependent manner $(P<0 \cdot 001)$. We conclude that IL-6 is a candidate signalling molecule in the chito-oligosaccharide-mediated inhibition of adipogenesis in 3T3-L1 cells.

\section{Key words: Fats: Functional foods: Inflammation: Obesity}

Obesity is characterised by the accumulation of excessive body fat, which is associated with a range of major diseases including type 2 diabetes, hypertension, CVD and arthritis ${ }^{(1)}$. Inhibition of adipogenesis through the ingestion of functional foods such as chitosan can reduce the deposition of excessive fat in adipose tissue ${ }^{(2,3)}$. Chitosan is a polymer of $\beta$ - $(1 \rightarrow 4)-2$ acetamido-D-glucose and $\beta$ - $(1 \rightarrow 4)$-2-amino-D-glucose ${ }^{(2,4)}$. It is synthesised through the chemical modification of chitin, which forms the hard shells of crustaceans such as crabs and shrimps ${ }^{(4,5)}$. Chitosan is a non-toxic nutritional supplement generally regarded as a safe compound ${ }^{(6-8)}$. Chitosan has been investigated for its therapeutic potential as an antiobesity, anti-microbial and antioxidant agent ${ }^{(3,9)}$. Recent studies have indicated that chitosan can inhibit absorption of lipids in human subjects and animals, which is based on the fact that chitosan can readily bind dietary lipids in the proximal region of the small intestine of the mammalian gastrointestinal tract ${ }^{(3,10-12)}$.

Native chitosan polymers generally have a very high molecular weight (MW). It is associated with low solubility and high viscosity, which limits its cellular absorption ${ }^{(12,13)}$. Hence, to enhance biological activity, chitosan is often modified to form chito-oligosaccharide, which has a lower MW, lower viscosity and higher solubility ${ }^{(14,15)}$. Chito-oligosaccharide can be absorbed by mammalian cells and can participate in metabolic processes within a cell ${ }^{(8,12,16)}$. However, the degree of absorption and intracellular activity of chitooligosaccharide is highly dependent on the MW, solubility and deacetylation percentage $e^{(7,8,12)}$, with low-MW chitooligosaccharide readily absorbed by intestinal cells in vitro and in vivo ${ }^{(8,12)}$.

The murine 3T3-L1 pre-adipocyte cell line has previously been used as an in vitro model system for investigating the

\footnotetext{
Abbreviations: ADIPOQ, adiponectin; cDNA, complementary DNA; CEBP $\alpha$, CCAAT/enhancer-binding protein- $\alpha$; CEBP $\beta$, CCAAT/enhancer-binding protein- $\beta$; DMEM, Dulbecco's modified Eagle's medium; GAPDH, glyceraldehyde 3-phosphate dehydrogenase; GUSB, $\beta$-glucuronidase; HPRT1, hypoxanthine guanine phosphoribosyl transferase 1; MW, molecular weight.
} 
molecular mechanisms of adipogenesis ${ }^{(17-19)}$. These fibroblast cells can be stimulated to differentiate into mature adipocytes, a process which mimics the maturation of adipose precursor cells and deposition of lipids during the development of obesity in humans ${ }^{(20)}$. In addition to playing a vital endocrine role in energy homeostasis, adipocytes are the primary sites of energy storage, where the excess energy is stored in the form of $\mathrm{TAG}^{(21)}$. Recent studies have demonstrated that chitooligosaccharides have the potential to alter the expression level of a number of genes involved in adipogenesis, including $P P A R \gamma$, CCAAT/enhancer-binding protein $(C E B P \alpha)$, leptin, adiponectin $(A D I P O Q)$ and resistin in adipocytes and mouse models ${ }^{(3,22)}$.

Adipogenesis occurs through the activation of biochemical pathways mediated through signalling molecules including cytokines, chemokines and adipokines ${ }^{(23,24)}$. One of the fundamental biochemical pathways vital to adipogenesis is the lipid metabolic pathway. The mode of action of chito-oligosaccharide as an anti-adipogenic compound has not yet been characterised. We hypothesised that anti-adipogenic chito-oligosaccharides will alter the expression of genes involved in the lipid metabolic pathway. Hence, the objectives of the present study were, first, to evaluate four chito-oligosaccharides for their concentration- and MW-dependent effects on the adipogenesis of mouse 3T3-L1 pre-adipocyte cells. Having identified the chito-oligosaccharide with the greatest anti-adipogenic potential, we subsequently evaluated its effect on the expression of a panel of genes involved in lipid metabolism and further validated the expression and regulation of the differentially expressed candidate gene at protein and gene promoter levels.

\section{Materials and methods}

\section{Cell culture}

Mouse 3T3-L1 pre-adipocytes were obtained from the American Type Culture Collection (Manassas, VA, USA). Cells were cultured in a Dulbecco's modified Eagle's medium (DMEM; Gibco, Invitrogen Corporation, San Diego, CA, USA) containing $10 \%$ fetal calf serum (Gibco) and $1 \%$ penistrep solution (Sigma-Aldrich Corporation, St Louis, MO, USA) in a $37^{\circ} \mathrm{C}$ humidified incubator with $5 \% \mathrm{CO}_{2}$. During the multiplication phase of the pre-adipocytes, the medium was changed every alternate day and the cells were trypsinised before reaching full confluence and were plated afresh.

\section{Chito-oligosaccharides}

A total of four chito-oligosaccharides of MW $<1000$, 10003000 (1-3000), 3000-5000 (3-5000) and 5000-10000 (5-10 000) Da were sourced from Kitto Life Company Limited (Kyungki-do, Seoul, Korea). Both the chito-oligosaccharide content and the deacetylation percentage of all of these chito-oligosaccharides were $>70 \%$. For the cell culture experiment, chito-oligosaccharide stock solution $(100 \mathrm{mg} / \mathrm{ml})$ was made using DMEM basal medium and introduced at final concentrations of $600,1200,2400$ and $4800 \mu \mathrm{g} / \mathrm{ml}$. DMEM basal medium was used as a carrier control. This range of concentration was based on a previous study where a concentration of $4000 \mu \mathrm{g} / \mathrm{ml}$ chito-oligosaccharide was used in the mouse 3T3-L1 cells and no adverse cytotoxic effect has been reported $^{(3)}$.

\section{Cell viability and cytotoxicity test}

Initially, cell viability and cytotoxicity of the mouse 3T3-L1 cells were assessed in response to a range of concentrations of the different MW chito-oligosaccharides. 3T3-L1 cells were plated in a ninety-six-well cell culture plate (Greiner BioOne Gmbh, Frickenhausen, Germany) at an initial plating density of $6 \times 10^{4}$ cells $/ \mathrm{ml}$. First, the cells were allowed to reach full confluence and then kept at a fully confluent state for $24 \mathrm{~h}$ before treating with chito-oligosaccharide. On the day of treatment, cells were washed with sterile PBS (SigmaAldrich) and incubated with serum- and antibiotic-free medium, containing chito-oligosaccharide at final concentrations of $0,600,1200,2400$ and $4800 \mu \mathrm{g} / \mathrm{ml}$, for 24 and $48 \mathrm{~h}$. Cell viability test was performed on the cell monolayer, using the 3-(4,5-dimethyl-2-yl)-2,5-diphenyltetrazolium bromide (Sigma-Aldrich) test. Cell cytotoxicity was evaluated with $25 \mu$ l cell lysate, using the Tox-7 kit (Sigma-Aldrich).

\section{Assessment of the anti-adipogenic potential of chito-oligosaccharides}

Cells were cultured to full confluence and adipogenesis was induced in the presence of a range of concentrations of chito-oligosaccharide. Intracellular lipid accumulation was visualised, free glycerol was measured and the quantitative expression of four adipogenic marker genes was determined and compared with untreated cells, as described below.

\section{Adipogenesis}

Mouse 3T3-L1 cells $\left(6 \times 10^{4}\right.$ cells $\left./ \mathrm{ml}\right)$ were cultured in DMEM containing $10 \%$ fetal calf serum and $1 \%$ penistrep solution in a twelve-well cell culture plate (Greiner Bio-One Gmbh) in a $37^{\circ} \mathrm{C}$ humidified incubator with $5 \% \mathrm{CO}_{2}$. Before induction of adipogenesis, the pre-adipocytes were allowed to reach full confluence and grown for $48 \mathrm{~h}$. Adipogenesis was induced (day 0 ) by introducing the DMEM containing $10 \%$ fetal bovine serum (Gibco), 0.5 mm-3-isobutyl-1-methylxanthine (Sigma-Aldrich), 0.25 $\mu \mathrm{m}$-dexamethasone (Sigma-Aldrich) and bovine insulin $(10 \mu \mathrm{g} / \mathrm{ml}$; Sigma-Aldrich) and $1 \%$ penistrep (differentiation induction medium). After $48 \mathrm{~h}$ of incubation with the induction medium (day 2), the medium was removed and post-differentiation medium (DMEM, 10\% fetal bovine serum, bovine insulin $(5 \mu \mathrm{g} / \mathrm{ml})$ and $1 \%$ penistrep) was introduced and incubated for $48 \mathrm{~h}$. Then (day 4 ), the postdifferentiation medium was removed and the cells were grown in DMEM containing $10 \%$ fetal bovine serum and $1 \%$ penistrep, and the medium was changed after every $48 \mathrm{~h}$ until the cells were harvested at day 8 of induction of adipogenesis. During the process of adipogenesis, chito-oligosaccharides were added to the medium in every

\footnotetext{
centrations of $600,1200,2400$ and $4800 \mu \mathrm{g} / \mathrm{ml}$. DMEM basal
} 
alternate day from day 0 to 8 at final concentrations of 0,600 , 1200,2400 and $4800 \mu \mathrm{g} / \mathrm{ml}$.

\section{Determination of lipid accumulation}

At day 8 of induction of adipogenesis, the medium was removed and the cells were washed using sterile PBS (Sigma-Aldrich) and then fixed by using $10 \%$ formalin solution (Sigma-Aldrich). Oil Red $\mathrm{O}$ staining of the adipocytes was performed as described previously ${ }^{(25)}$. Counter staining was performed using $1 \mathrm{ml}$ of haematoxylin (Sigma-Aldrich) solution per well. The adipocytes were evaluated under a microscope and the image captured were analysed using Image-Pro 5.0 software (Media Cybernetics, Inc., Bethesda, MD, USA). Six random microscopic fields per treatment were captured at a microscopic resolution of $10 \times$ and the Oil Red O stain was quantified and is expressed as the ratio of the area stained with Oil Red $O$ and the total area of the microscopic field.

\section{Determination of free glycerol}

Glycerol release by the adipocyte is an indirect reflection of the TAG status of the cell ${ }^{(26,27)}$. Free glycerol estimation was performed on the medium harvested at day 8 of the induction of adipogenesis. Free glycerol was estimated on $5 \mu$ l of the cell lysate using the Enzychrom glycerol assay kit (BioAssay Systems, Hayward, CA, USA), following the manufacturer's instructions.

\section{RNA extraction}

To compare the expression of four adipogenic marker genes in the cells following exposure to the different MW chito-oligosaccharides, RNA was extracted from the cells, complementary DNA (cDNA) was synthesised and used for quantitative realtime PCR analyses. At day 8 of induction of adipogenesis, the medium was removed and the cell monolayer was washed with sterile PBS and the cells were collected in $1 \mathrm{ml}$ TRI reagent (Applied Biosystems, Foster City, CA, USA). Total RNA was extracted using the Trizol method according to the manufacturer's instructions. RNA was dissolved in $20 \mu \mathrm{l}$ of nuclease-free water and then subjected to deoxyribonuclease I (Sigma-Aldrich) treatment to eliminate the genomic DNA contamination. Column purification of RNA was performed using the GenElute mammalian total RNA miniprep kit (SigmaAldrich). RNA was finally eluted in $40 \mu \mathrm{l}$ of nuclease-free water. The quality and quantity of total RNA were assayed by analysing $1 \mu \mathrm{l}$ of total RNA on an Agilent 2100 Bioanalyser (Agilent Technologies, Inc., Santa Clara, CA, USA) using RNA Nano LabChips ${ }^{\circledR}$ (Caliper Technologies Corporation, Hopkinton, MA, USA). All RNA samples used for the gene expression study had an RNA integrity value $\geq 8 \cdot 0$.

\section{Quantitative real-time $P C R$}

cDNA synthesis was performed with $1 \mu \mathrm{g}$ of total RNA, using the RevertAid $\mathrm{H}$ minus first-strand cDNA synthesis kit (Fermentas GmbH, St Leon-Rot, Germany) following the manufacturer's protocol. The quantitative expressions of four adipogenic marker genes (glyceraldehyde 3-phosphate dehydrogenase $(G A P D H), P P A R \gamma, C E B P \alpha$ and $A D I P O Q)$ and $\beta$-actin $(A C T B)$ as a reference gene were evaluated using a 7300 Real-Time PCR System (Applied Biosystems). The PCR mixture $(20 \mu \mathrm{l})$ contained $1 \mu \mathrm{l}$ cDNA (after 1:5 dilution), $1 \mu \mathrm{l}$ forward and reverse primer mix, $8 \mu 1$ water and $10 \mu \mathrm{S}$ SYBR green master mix (Applied Biosystems). The thermal cycle conditions were $94^{\circ} \mathrm{C}$ for $30 \mathrm{~s}$, followed by $60^{\circ} \mathrm{C}$ for $1 \mathrm{~min}$, for forty cycles. The mRNA abundances are expressed in $C_{\mathrm{t}}$ values, the number of PCR cycles after which the PCR product crosses a threshold value. Each sample was run in triplicate and $C_{\mathrm{t}}$ values $<35$ were used for analysis.

\section{Identification of molecular mechanisms of action of chito-oligosaccharides}

Based on the results obtained on the anti-adipogenic potential of the chito-oligosaccharides, 3T3-L1 cells were treated with one chito-oligosaccharide (MW 5-10000 Da) at a range of final concentrations of $0,600,2400$ and $4800 \mu \mathrm{g} / \mathrm{ml}$. The gene expression profile of forty-four genes involved in the mouse lipid metabolic pathway was assessed in these cells. As the $I L-\sigma$ gene was identified as the most sensitive gene of the forty-four genes analysed, the $I L-6$ gene expression data were validated at the protein level, using an ELISA assay. An $I L-6$ promoter assay was also developed to determine whether the promoter activity would reflect the gene expression data. The details of these methods are outlined below.

\section{Lipid metabolic pathway genes}

The quantitative expression of a panel of genes involved in lipid metabolism in mice was evaluated using 'TaqMan Array for Mouse Lipid Regulated Genes 96-Well Plate' (Applied Biosystems) in a 7300 Real-Time PCR System (Applied Biosystems). This is a pre-customised array, which enables screening of forty-four different genes involved in mouse lipid metabolism. According to the manufacturer, the genes included in this array had either established or a potential role in lipid metabolism, and hence it was considered suitable to screen chito-oligosaccharide-mediated inhibition of adipogenesis. Real-time RT-PCR was performed in a $20 \mu \mathrm{l}$ reaction mixture/well containing $1 \mu \mathrm{l}$ cDNA (after 1:5 dilution), $9 \mu \mathrm{l}$ water and $10 \mu \mathrm{l}$ TaqMan gene expression master mix (Applied Biosystems). The thermal cycle conditions used were as stated above.

Normalisation of the expression of the target genes included in the PCR array was performed based on two reference genes (hypoxanthine guanine phosphoribosyl transferase 1 (HPRT1) and $\beta$-glucuronidase (GUSB) and following the $2^{-\Delta \Delta C_{\mathrm{t}}}$ method $^{(28)}$. Briefly, average $\Delta C_{\mathrm{t}}$ was calculated as the difference of $C_{\mathrm{t}}$ values of any target gene minus average of the $C_{\mathrm{t}}$ value of the two reference genes. Then, fold change was calculated as $2^{\left(- \text {average } \Delta C_{\mathrm{t}} \text { target gene) }\right.} / 2^{\left(- \text {average } \Delta C_{\mathrm{t}} \text { reference gene) }\right.}$. 


\section{Promoter activation assay}

Promoter construct. A 1065 bp fragment of the regulatory region (stretching from -1064 to $+1 \mathrm{bp}$ relative to the transcription start site) of the human $I L-6$ gene was amplified by PCR. The forward primer (5'-CCTTAGATCTCTGCGTCCGTAGTTTCCTTC- $3^{\prime}$ ) was designed to include a $B g l$ II restriction site (italicised). The reverse primer (5'-GAGTAAGCTTTGAGCCTCAGACATCTCCAG- $3^{\prime}$ ) incorporated a Hind III restriction enzyme site (italicised) plus a four-nucleotide anchor at the $5^{\prime}$ end. PCR amplification was performed in a PTC-225 DNA Engine Tetrad (MJ Research, Inc., Waltham, MA, USA) using 1X Platinum PCR SuperMix High fidelity (Invitrogen Corporation), $0 \cdot 2 \mu \mathrm{M}$ of each of the forward and reverse primers and $50 \mathrm{ng}$ of human genomic DNA (Promega Corporation, Madison, WI, USA) in a total volume of $100 \mu \mathrm{l}$. The PCR cycle conditions were as follows: initial $94^{\circ} \mathrm{C}$ for $2 \mathrm{~min}$ followed by thirty-nine cycles of $94^{\circ} \mathrm{C}$ for $45 \mathrm{~s}, 60^{\circ} \mathrm{C}$ for $45 \mathrm{~s}$ and $70^{\circ} \mathrm{C}$ for $1 \mathrm{~min}$ followed by a final extension of $72^{\circ} \mathrm{C}$ for $10 \mathrm{~min}$. The PCR product (1065 bp) was assessed on a $1.3 \%$ agarose gel stained with ethidium bromide. Cloning of the PCR product into firefly luciferase expression vector pGL4.17 (Promega Corporation) was performed, as described previously ${ }^{(29)}$. Transfection-grade endotoxin-free plasmid construct containing the human $I L-6$ promoter insert was prepared using the EndoFree Plasmid Maxi kit (Qiagen, Chatsworth, CA, USA).

\section{Cell culture and transient transfection assay}

The day before the transfection assay, 3T3-L1 cells $\left(6 \times 10^{4}\right.$ cells $/ \mathrm{ml}$ ) were initially cultured in DMEM containing $10 \%$ fetal calf serum in a twenty-four-well cell culture plate (Greiner Bio-One $\mathrm{GmbH}$ ) in a $37^{\circ} \mathrm{C}$ humidified incubator with $5 \% \mathrm{CO}_{2}$. The transfection cocktail (for each well) contained $25 \mu \mathrm{l}$ DMEM basal medium, 0.3 $\mathrm{l}$ l FuGENE HD transfection reagent (Roche Diagnostics GmbH, Mannheim, Germany) and $100 \mathrm{ng}$ of $I L-6$ promoter construct DNA. Following incubation at room temperature for $15 \mathrm{~min}$, this cocktail was introduced dropwise onto the cells. The cells were grown on a DMEM containing $10 \%$ fetal calf serum until the fully confluent state was attained. After $48 \mathrm{~h}$ of attaining full confluence, the cells were treated with chito-oligosaccharide in (1) a serum-free basal medium or (2) a serum-containing differentiation induction medium, as described earlier.

Transiently transfected cells were allowed to grow for $24 \mathrm{~h}$ and luciferase assay was performed using the Luciferase Reporter Assay system (Promega Corporation). In brief, the medium was removed and the cells were washed with $500 \mu \mathrm{l}$ PBS. Lysis of the cells was performed by adding $250 \mu \mathrm{l}$ of passive lysis buffer (Promega Corporation), followed by incubation at $37^{\circ} \mathrm{C}$ in a shaking incubator for $30 \mathrm{~min}$ at $700 \mathrm{rpm}$. Firefly-relative luciferase unit activity was measured in $20 \mu \mathrm{l}$ of the cell lysate in a 20/20n Single Tube Luminometer (Turner Biosystems, Inc., Sunnyvale, CA, USA).

\section{IL-6 ELISA}

To support the gene expression data, a time-course study was set up to measure the IL- 6 protein levels in the medium over the course of the experiment. The cell culture medium was harvested at days 2, 4 and 8 of the induction of adipogenesis and stored at $-80^{\circ} \mathrm{C}$ until used for analysis. Abundance of IL-6 in the culture medium was measured using the mouse IL-6 duo set ELISA development system (R\&D Systems Europe, Limited, Abingdon, UK), following the manufacturer's instructions. Absorbance was measured at $450 \mathrm{~nm}$ against $570 \mathrm{~nm}$ using the ELISA plate reader. The assay was performed in duplicate for each sample.

\section{Statistical analysis}

For the Oil Red O data, each data point of the three independent assays represents the mean of six random microscopic fields per treatment. The Oil Red $\mathrm{O}$ and free glycerol data are expressed relative to the control sample that contained no chito-oligosaccharide. Data for all the variables were checked for a normal distribution. Oil Red $\mathrm{O}$ and free glycerol data were analysed using two-way ANOVA and the statistical model included the effect of concentration, MW and the interaction between concentration and MW. Within each concentration or MW, the means were compared by Tukey's test. The adipogenic marker gene expression, ELISA and promoter assay data were analysed using one-way ANOVA and the means were compared by Tukey's test. Values are expressed as means with their standard errors or standard errors of the difference of the mean, as appropriate.

\section{Results}

\section{Cell viability and cytotoxicity}

The effects of the four chito-oligosaccharides on the viability and cytotoxicity of confluent 3T3-L1 pre-adipocyte in serum-free medium are presented in the supplementary material (available online at http://www.journals.cambridge.org/bjn). For the cell viability test, the interaction effect of concentration $\times$ MW was non-significant for both 24 and $48 \mathrm{~h}$. After $24 \mathrm{~h}$ of incubation, concentration had a significant $(P<0.001)$ effect on cell viability, while cell viability dropped when treated with $4800 \mu \mathrm{g} / \mathrm{ml}$ of all chito-oligosaccharides. The MW had no effect at $24 \mathrm{~h}$. After $48 \mathrm{~h}$ of incubation, the concentration and MW had significant effects $(P<0.001)$ on cell viability. Cell viability was most affected with $4800 \mu \mathrm{g} / \mathrm{ml}$ of oligosaccharide and least affected by the MW 5-10000 Da after $48 \mathrm{~h}$. For cell cytotoxicity, after $24 \mathrm{~h}$ of incubation with chito-oligosaccharide, neither concentration nor MW had any effect. However, after $48 \mathrm{~h}$ of incubation, the concentration and MW had significant effects $(P<0 \cdot 001)$. Cell cytotoxicity was most affected with $4800 \mu \mathrm{g} / \mathrm{ml}$ of chito-oligosaccharide and least affected by the MW 5-10000 Da after $48 \mathrm{~h}$.

\section{Inhibition of adipogenesis}

The semi-quantitative data on Oil Red O staining (Fig. 1) suggested that chito-oligosaccharides had a concentration- and 


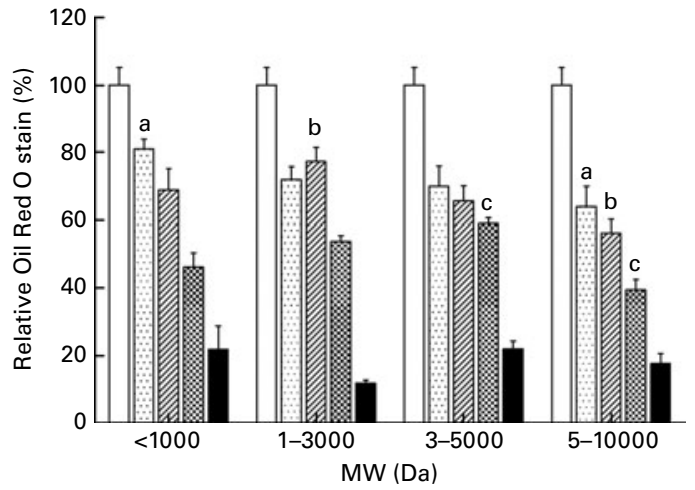

Fig. 1. Effects of chito-oligosaccharide on lipid synthesis in mouse 3T3-L1 adipocytes during adipogenesis. Cells were induced to differentiate in the presence of chito-oligosaccharide (molecular weight (MW) $<1000,1000-$ $3000,3000-5000$ and $5000-10000 \mathrm{Da}$ ). Lipid synthesised during adipogenesis was stained with Oil Red $O$ stain at day 8 of induction of differentiation. The data are expressed relative to the chito-oligosaccharide control $(0 \mu \mathrm{g} / \mathrm{ml})$ group (two-way ANOVA: concentration effect $P<0.001$; MW $P<0.05$ ). Values are means from three independent replications, with standard errors represented by vertical bars. ${ }^{a, b, c}$ Mean values with the same letters are significantly different in concentrations of different MW chito-oligosaccharide

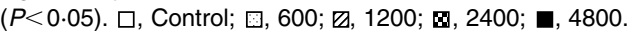

MW-dependent inhibitory effect $(P<0.001$ and $<0.05)$ on lipid synthesis. Compared with the control sample $(0 \mu \mathrm{g} / \mathrm{ml}$ chito-oligosaccharide), the mean percentage of lipid synthesis values at $600,1200,2400$ and $4800 \mu \mathrm{g} / \mathrm{ml}$ of chito-oligosaccharides were $71 \cdot 1,66 \cdot 1,49 \cdot 5$ and 18.8 (SED $3 \cdot 24)$, respectively. On the other hand, the mean percentage of lipid synthesis values for $<1000,1-3000,3-5000$ and $5-10000 \mathrm{Da}$ chito-oligosaccharides were $53 \cdot 3,53 \cdot 7,52 \cdot 7$ and $45 \cdot 0$ (SED 3.22), respectively. Among the four chitooligosaccharides evaluated, 5-10000 Da had the highest inhibitory effect on lipid synthesis (Fig. 1). The interaction effect of concentration $\times$ MW on the relative Oil Red $\mathrm{O}$ stain was not significant. The concentration effect of one chito-oligosaccharide $(5-10000 \mathrm{Da})$ at the single-cell level $(40 \times$ resolution) and that of four chito-oligosaccharides, as observed in the microscopic field $(10 \times$ resolution), are presented in Fig. 2(a) and (b), respectively. It was evident that the control had a large number of intracellular lipid droplets, while those treated with $600-4800 \mu \mathrm{g} / \mathrm{ml}$ of various MW chito-oligosaccharides had a visible reduction in the number and size of the lipid droplets.

\section{Free glycerol release}

The effect of chito-oligosaccharide on free glycerol release during adipogenesis is presented in Fig. 3. Chito-oligosaccharides had a concentration-dependent inhibitory effect $(P<0.001)$ in free glycerol release, which was not affected by the MW. Compared with the control sample, the relative free glycerol release at $600,1200,2400$ and $4800 \mu \mathrm{g} / \mathrm{ml}$ of chito-oligosaccharide was $76.0,66.8,52.6$ and $41.8 \%$

(a)
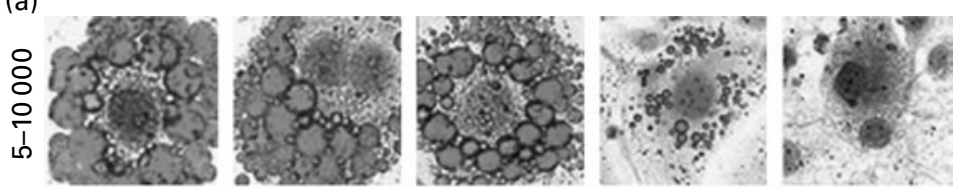

(b)

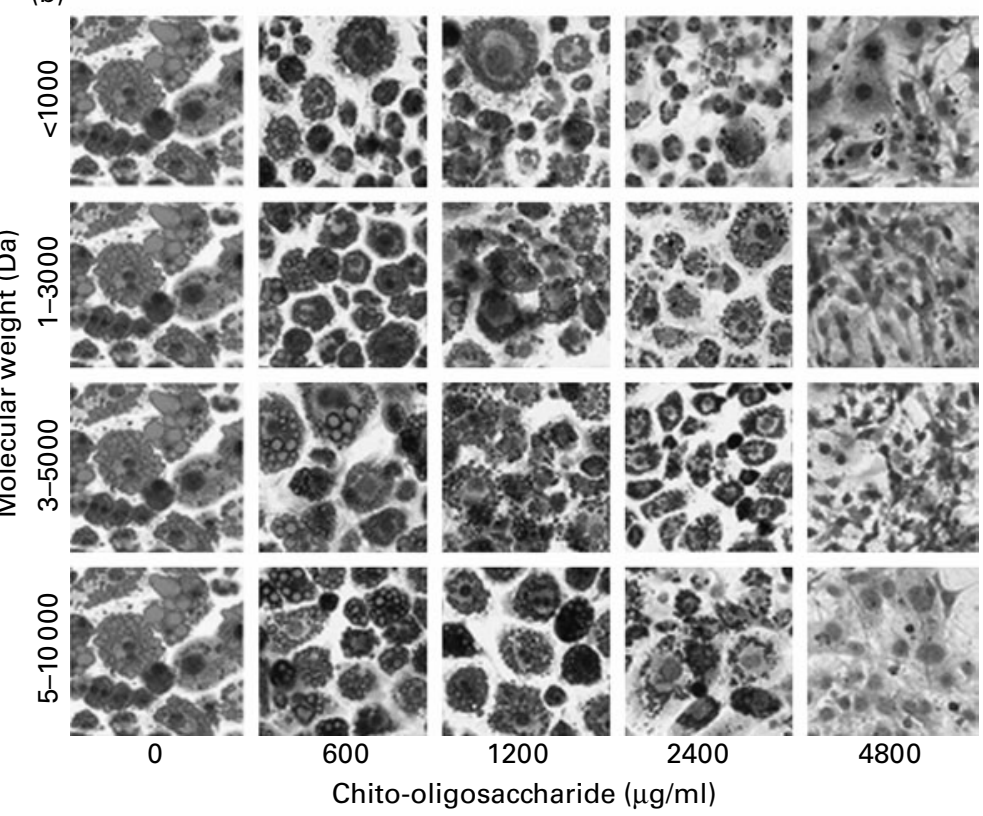

Fig. 2. (a) Effects of chito-oligosaccharide treatment on the adipogenesis of mouse $3 T 3-L 1$ pre-adipocytes at the single-cell level (40X resolution). Cells were induced to differentiate in the presence of chito-oligosaccharide (molecular weight $<1000,1-3000,3-5000$ and $5-10000 \mathrm{Da}$ ). (b) Lipid synthesised during adipogenesis was stained with Oil Red $O$ stain at day 8 of induction of differentiation (10 $\times$ resolution). 


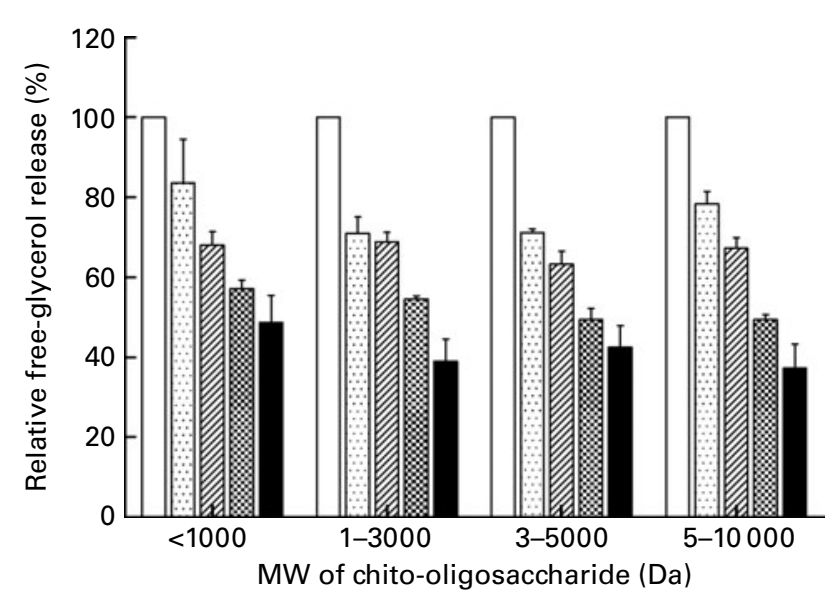

Fig. 3. Effects of chito-oligosaccharide on free glycerol release during adipogenesis. Mouse 3T3-L1 pre-adipocytes were induced to differentiate in the presence of four different chito-oligosaccharides (molecular weight (MW) $<1000,1-3000,3-5000$ and 5-10 000 Da) (two-way ANOVA: concentration effect $P<0.001 ;$ MW $P=N S$ ). Free glycerol release in the medium was estimated at day 8 of induction of adipogenesis. The data are expressed relative to the chito-oligosaccharide control $(0 \mu \mathrm{g} / \mathrm{ml})$ group. Values are means from three independent replications, with standard errors represented by vertical bars. $\square$, Control; $\square, 600 ; \square, 1200 ; \mathbf{⿴ 囗 十 , ~ 2 4 0 0 ; ~ \square , ~} 4800$.

(SED 3.00), respectively. The interaction effect of concentration $\times$ MW on free glycerol release was not significant.

\section{Quantitative expression of adipogenic marker genes}

The effect of chito-oligosaccharide (MW 5-10 $000 \mathrm{Da}$ ) on the quantitative expression of the four adipogenic marker genes during adipogenesis is presented in Fig. 4. For all the four marker genes, the control $(0 \mu \mathrm{g} / \mathrm{ml}$ chito-oligosaccharide) had the highest level of the abundance of gene transcripts, while treatment with chito-oligosaccharide (600, 1200, 2400 and $4800 \mu \mathrm{g} / \mathrm{ml}$ ) resulted in a significant reduction in the transcript abundance level of all the four marker genes in a concentration-dependent manner.

\section{Expression profiling of lipid metabolic genes}

Based on the lipid synthesis inhibition profile of the four chitooligosaccharides, the MW 5-10 000 Da was evaluated across the concentrations 600,2400 and $4800 \mu \mathrm{g} / \mathrm{ml}$ for the regulation of gene expression. The quantitative expression of a total of forty-four genes involved in mouse lipid metabolism is presented in Fig. 5. These forty-four genes evaluated had either established or a potential role in lipid metabolism, and hence chosen for identifying the genes with modified expression during the chito-oligosaccharide-mediated inhibition of adipogenesis. Across the concentrations tested, the expression level of $I L-6$ and PTGS2 (also known as cyclo-oxygenase-2) genes had a concentration-dependent increase with chito-oligosaccharide. Compared with the control, at concentrations 600, 2400 and $4800 \mu \mathrm{g} / \mathrm{ml}$, the expression level of $I L-6$ gene was up by $4 \cdot 2,7 \cdot 3$ and $21 \cdot 2$-fold, respectively (Table 1 ). This expression pattern of the $I L-6$ gene across the concentration of chito-oligosaccharides indicated an exponential increase (fold change $\left.=3.149 \mathrm{e}^{0.0004(\text { chito-oligosaccharide }(\mu \mathrm{g} / \mathrm{ml}))}, r^{2} 0.99\right)$. The expression level of PTGS2 was also up by $4 \cdot 2-$ and 16.9-fold at the chito-oligosaccharide concentrations of 2400 and $4800 \mu \mathrm{g} / \mathrm{ml}$, respectively (Table 1). Down-regulation in the expression of a total of twelve genes, mostly involved in lipid biosynthesis (Fig. 5), was only evident at the chitooligosaccharide concentration of $4800 \mu \mathrm{g} / \mathrm{ml}$.

\section{IL-6 promoter transcriptional activity}

The stimulatory effect of chito-oligosaccharide on $I L-6$ gene promoter activity in transiently transfected mouse 3T3-L1 cells (at a post-confluent state) is presented in Fig. 6. IL-6 promoter transcriptional activity increased $(P<0.001)$ due to the chito-oligosaccharide treatment in both serum-containing and serum-free cellular environments. Higher levels of $I L-6$ promoter activity were evident in the serum-containing differentiation medium than in the serum-free medium.

\section{IL-6 ELISA}

The abundance of IL- 6 at day 8 post-induction of differentiation in the presence of chito-oligosaccharide $(5-10000 \mathrm{Da})$ is presented in Fig. 7. The presence of chito-oligosaccharide resulted in the secretion of IL- 6 in the cell culture medium in a concentration-dependent manner. While the cells treated with $0 \mu \mathrm{g} / \mathrm{ml}$ of chito-oligosaccharide had only 1.69 (SEM $0.39) \mathrm{pg} / \mathrm{ml}$ of IL- 6 in the medium, those treated with 600 , 1200, 2400 and $4800 \mu \mathrm{g} / \mathrm{ml}$ of chito-oligosaccharide had $26 \cdot 39$ (SEM 2.41), 25.78 (SEM 2.54), 33.13 (SEM 1.38) and 63.28 (SEM $51 \cdot 6) \mathrm{pg} / \mathrm{ml}$ of IL-6 $(P<0 \cdot 001)$. Secretion of IL-6 over time by the differentiating 3T3-L1 cells in the presence of chito-oligosaccharide $(2400 \mu \mathrm{g} / \mathrm{ml})$ is presented in Fig. 8. At $0-48 \mathrm{~h}$ post-induction of adipogenesis, chito-oligosaccharide caused a sixteen-fold increase in IL- 6 secretion compared with the control. During the 48-96 and 96-144h periods, although IL-6 secretion was relatively small compared with $0-48 \mathrm{~h}$ post-induction of differentiation, the level of IL- 6 secretion was considerably high relative to the control samples.

\section{Discussion}

Adipogenesis is a vital physiological process, with excessive adipogenesis contributing to the development of obesity. In the present study, all four chito-oligosaccharides examined had concentration-dependent anti-adipogenic activities, with the 5-10000 Da chito-oligosaccharide having the most pronounced inhibitory effect on lipid accumulation. To understand the cell-signalling events of the chito-oligosaccharidemediated inhibition of adipogenesis, the expression of a panel of genes in the lipid metabolic pathway was evaluated. These data suggest that during the chito-oligosaccharidemediated inhibition of adipogenesis, up-regulation of the $I L-6$ gene, and at higher chito-oligosaccharide concentrations, the PTGS2 gene, occurred in a concentration-dependent manner. Stimulatory activity of chito-oligosaccharide on the regulation of the $I L-6$ gene was also evident at transcription 
(a)

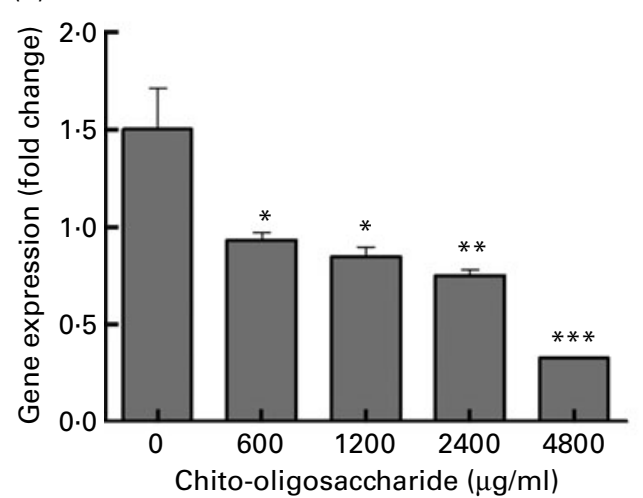

(c)

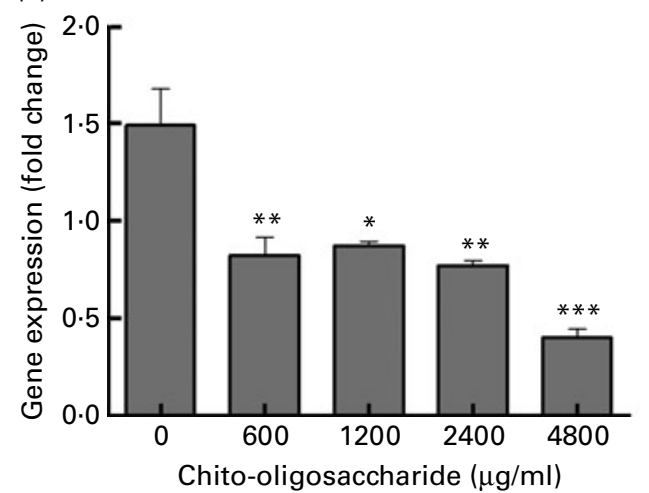

(b)

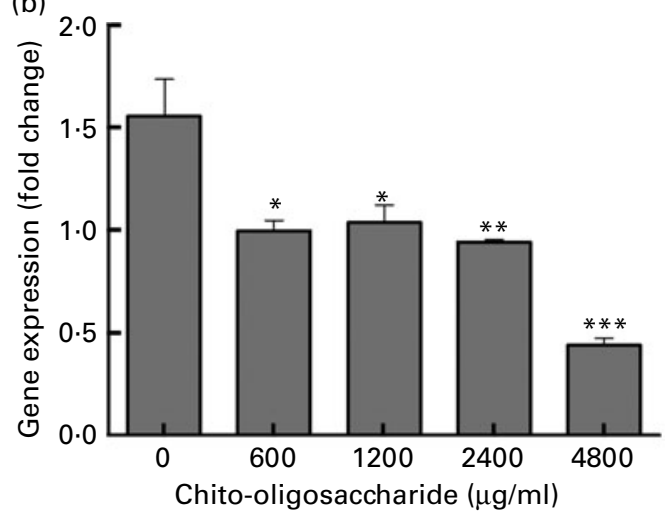

(d)

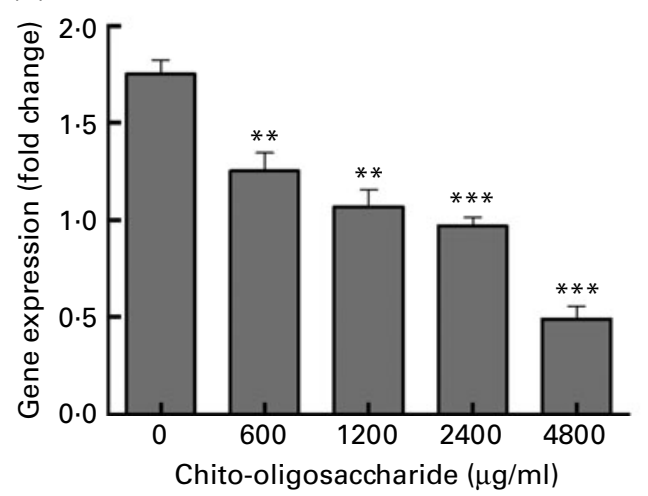

Fig. 4. Effect of chito-oligosaccharide (molecular weight 5-10000 Da) on the expression of adipogenic marker genes (a) glyceraldehyde 3-phosphate dehydrogenase; (b) CCAAT-enhancer-binding protein; (c) PPARG; (d) adiponectin. during adipogenesis. Mouse 3T3-L1 pre-adipocytes were induced to differentiate in the presence of chito-oligosaccharide. At day 8 of induction of differentiation, cells were harvested and total RNA was extracted and the relative abundance of the adipogenic marker genes were determined using quantitative real-time RT-PCR. Values are means from three independent replications, with standard errors represented by vertical bars. Mean values are significantly different compared with the chito-oligosaccharide control $(0 \mu \mathrm{g} / \mathrm{ml}) \mathrm{group}$ for each gene: ${ }^{\star} P<0.05$, ${ }^{\star *} P<0.01,{ }^{* \star *} P<0.001$.

and translation levels. The results of the present study suggest that elevated expression levels of the pro-inflammatory cytokine IL-6, as well as PTGS2, are among the signalling molecules likely to have a fundamental role in the chitooligosaccharide-mediated inhibition of adipogenesis.

The anti-adipogenic potential of chito-oligosaccharide was found to be influenced by the MW, where the 5-10000 Da chito-oligosaccharide had the most pronounced inhibitory effect on lipid accumulation. It also had a better cell viability and cytotoxicity profile in comparison with the other MW chito-oligosaccharide. With regard to the anti-adipogenic potential of different MW chito-oligosaccharides, two previous studies have reported varying information. Similar to the present results, Qin et al. reported 5-10000 Da to be more effective in weight reduction in mice compared with low $(<1000 \mathrm{Da})$ and medium $(1-3000 \mathrm{Da})$ MW chitooligosaccharides. In contrast, $1-3000 \mathrm{Da}$ was found to be the most effective in inhibiting TAG release during adipogenesis in 3T3-L1 cells when 1-3000, 3-5000, 5-10000 Da and their mixture were compared $^{(3)}$. All four chito-oligosaccharides had concentration-dependent anti-adipogenic activities in the mouse 3T3-L1 pre-adipocytes, as reflected by the lipid accumulation (Oil Red $\mathrm{O}$ ) and free glycerol release data. The anti-adipogenic potential of chito-oligosaccharide (5-10000 Da) was further verified through quantifying the expression levels of four adipogenic marker genes (GAPDH, $C E B P \alpha, P P A R \gamma$ and $A D I P O Q)$, where the expression levels of these genes were down-regulated by the chito-oligosaccharide treatment. Profiling of mouse 3T3-L1 adipocytes treated with chito-oligosaccharide previously revealed that the inhibitory effect of chito-oligosaccharide on lipid synthesis is mediated by the modulation of adipokines and adipose tissue-specific genes such as CEBP $\alpha$ and $P P A R \gamma^{(30)}$.

To identify the potential candidate genes involved in the chito-oligosaccharide-mediated inhibition of adipogenesis in the mouse 3T3-L1 adipocytes, and to ascertain the key signalling pathways involved, we have evaluated the quantitative expression of a panel of lipid metabolic pathway genes. This panel included representation of genes for various pathways, including lipid biosynthesis and breakdown, cytokine, chemokines, adipokines and their receptors. The genes included in this array had either an established or a potential role in lipid metabolism - a vital metabolic process reportedly affected by chito-oligosaccharides ${ }^{(3)}$. This screening procedure enabled the identification of a total of fourteen differentially expressed genes. This included two cytokine genes (IL-6 and PTGS2) that were up-regulated and twelve genes, mostly involved in lipid breakdown, that were downregulated. 

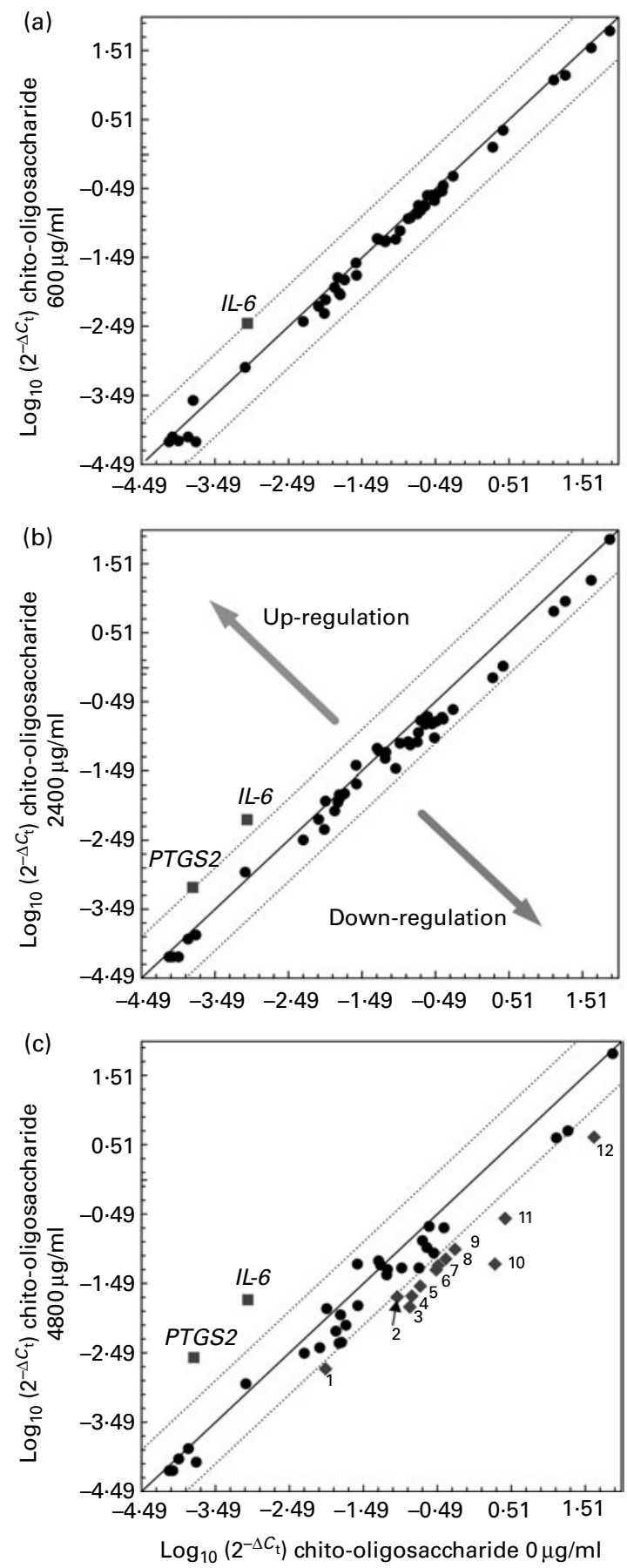

Fig. 5. Differential expression of mouse genes involved in the lipid metabolic pathways as induced by the treatment of chito-oligosaccharide (molecular weight 5-10 $000 \mathrm{Da}$ ) during adipogenesis. Mouse 3T3-L1 pre-adipocytes were induced to differentiate in the presence of chito-oligosaccharide. At day 8 of induction of differentiation, gene expression was analysed using the TaqMan PCR array. Relative abundances of complementary DNA in the samples treated with (a) 600, (b) 2400 (c) and $4800 \mu \mathrm{g} / \mathrm{ml}$ chito-oligosaccharide compared with the chito-oligosaccharide control group $(0 \mu \mathrm{g} / \mathrm{ml})$ are shown. 1, ATP-binding cassette, sub-family $\mathrm{G}$ (white), member 1; 2, 3-hydroxy-3-methylglutarylCoenzyme A synthase $1 ; 3$, apolipoprotein $\mathrm{E} ; 4$, fatty acid binding protein 5 ; 5 , nuclear receptor subfamily 1 , group $H$, member $3 ; 6$, hydroxyacyl-coenzyme A dehydrogenase/3-ketoacyl-coenzyme A thiolase/enoyl-coenzyme A hydratase (trifunctional protein); 7, leukotriene C4 synthase; 8, PPARG; 9, acyl-coenzyme A dehydrogenase, very long chain; 10 , stearoyl-coenzyme A desaturase 1; 11, CD36 antigen; 12, fatty acid binding protein 4.
While IL-6 is commonly known for its dual pro- and antiinflammatory functions, it clearly acts as an inhibitor of lipid accumulation and an inducer of fat lipolysis and oxidation in vivo ${ }^{(31-33)}$ and in vitro ${ }^{(34)}$. Transgenic mice deficient in the $I L-6$ gene were found to develop obesity and reverted back to normal once treated with IL- $6^{(31)}$. The anti-obesity action of IL-6 was reportedly mediated through an increase in the energy expenditure and breakdown of lipids ${ }^{(31)}$. Therefore, it may be likely that the high level of $I L-6$ gene expression in differentiating 3T3-L1 cells treated with chitooligosaccharide is actually responsible for the inhibition of lipid synthesis. Chito-oligosaccharide-mediated inhibition of lipid synthesis both in vitro and in vivo has been reported previously ${ }^{(3,35)}$, and the novel finding of the present study is that this inhibition is mostly probably mediated through the IL-6 signalling pathway.

The exact molecular mode of action of IL- 6 during the differentiation of pre-adipocytes is not well understood because of the fact that the previous studies on IL-6 used mature adipocytes. IL-6 can directly down-regulate the expression of a number of adipogenic markers, including $P P A R \gamma, C E B P \alpha$ and $A D I P O Q$ in adipocytes, which results in decreased adipocyte differentiation and an attenuation of lipid accumulation ${ }^{(36,37)}$. This IL-6-mediated suppression of key adipogenic marker genes was reportedly mediated through the mitogen-activated protein kinase extracellular signal-related kinases signalling pathway, which can lead to a reduction in TAG synthesis in adipocytes ${ }^{(37)}$. Therefore, in the present study, it is possible that the inhibitory role of chito-oligosaccharide on the expression of key adipogenic markers was, at least, partly due to a high level of IL-6 secretion by the 3T3-L1 cells in response to the chito-oligosaccharide treatment during the differentiation process.

In the present study, treatment of differentiating 3T3-L1 cells with chito-oligosaccharide (MW 5-10000 Da) resulted in an increase in the $I L-6$ gene expression and IL- 6 secretion in the medium across the concentrations tested $(600-4800 \mu \mathrm{g} /$ $\mathrm{ml}$ ). Although a concentration of $4800 \mu \mathrm{g} / \mathrm{ml}$ may be considered too high to attain, under physiological conditions, a concentration-dependent increase in the $I L-6$ gene and protein was evident even at low chito-oligosaccharide concentrations $(600$ and $2400 \mu \mathrm{g} / \mathrm{ml})$. Since the 5-10000 Da-treated cells had high cell viability and low cytotoxicity profiles, it is unlikely that the gene expression, ELISA and promoter activity results were a manifestation of cell cytotoxicity caused by chito-oligosaccharide.

Another interesting gene, whose expression level was upregulated by chito-oligosaccharide, was the PTGS 2 gene. An up-regulation of the PTGS2 gene was only evident at 2400 and $4800 \mu \mathrm{g} / \mathrm{ml}$ of chito-oligosaccharide, and hence this gene is not considered to be as sensitive as $I L-6$. In adipose cells, PG endoperoxidase synthase is involved in the conversion of arachidonic acid, which is derived from the membrane phospholipids, to $\mathrm{PG}^{(38)}$. In the 3T3-L1 cells, $\mathrm{PGE}_{2}$ was found to be abundantly produced at the rapidly growing sub-confluent state and its level gradually dropped when the cell reached the confluent state followed by a substantial reduction during the differentiation phase ${ }^{(39)}$. The authors 
Table 1. Regulation of the expression of lipid metabolic genes in mouse 3T3-L1 pre-adipocytes during adipogenesis as induced by chito-oligosaccharide (molecular weight 5-10000 Da)

\begin{tabular}{llcc}
\hline Chito-oligosaccharide $(\mu \mathrm{g} / \mathrm{ml})$ & Genes & Fold change & Regulation \\
\hline 600 & IL-6 & 4.15 & $\uparrow$ \\
2400 & IL-6 & 7.34 & $\uparrow$ \\
4800 & PTGS2 & 4.15 & $\uparrow$ \\
& IL-6 & 21.17 & $\uparrow$ \\
& PTGS2 & 16.94 & $\downarrow$ \\
& ABCG1 & -5.21 & $\downarrow$ \\
& ACADVL & -5.59 & $\downarrow$ \\
& APOE & -9.20 & $\downarrow$ \\
& CD36 & -9.61 & \\
& FABP4 (adipocyte) & & $\downarrow$ \\
& FABP5 (epidermal) & -10.17 & \\
& HMGCS1 & -6.85 & $\downarrow$ \\
& HADHB & -4.50 & \\
& LTC4S & -6.16 & $\downarrow$ \\
& NR1H3 & -5.70 & $\downarrow$ \\
& PPARG & -6.40 & $\downarrow$ \\
& SCD1 & -5.54 & $\downarrow$ \\
& & -31.51 & $\downarrow$ \\
& & & \\
& & &
\end{tabular}

PTGS2, prostaglandin-endoperoxide synthase-2; ABCG1, ATP-binding cassette, sub-family G (white), member 1; ACADVL, acyl-coenzyme A dehydrogenase, very long chain; APOE, apolipoprotein E; CD36, CD36 antigen; FABP4, fatty acid binding protein 4; FABP5, fatty acid binding protein 5; HMGCS1, 3-hydroxy-3-methylglutaryl-coenzyme A synthase 1; HADHB, hydroxyacyl-coenzyme A dehydrogenase/3-ketoacyl-coenzyme A thiolase/enoyl-coenzyme A hydratase (trifunctional protein), $\beta$-subunit; LTC4S, leukotriene C4 synthase; NR1H3, nuclear receptor subfamily 1 , group $\mathrm{H}$, member 3; SCD1, stearoyl-coenzyme A desaturase 1 ; $\uparrow$, up-regulation; $\downarrow$, down-regulation.

have suggested that cessation of cell growth at the confluent state and differentiation phases were associated with the inhibition of $\mathrm{PGE}_{2}$ production. $\mathrm{PGE}_{2}$ has also been reported to be a suppressor of the differentiation of 3T3-L1 pre-adipocyte ${ }^{(40)}$. In diet-induced obesity of mice, $\mathrm{PGE}_{2}$ was less abundant in the tissue obtained from obese mice compared with lean mice ${ }^{(41)}$. In obese human subjects, $\mathrm{PGE}_{2}$ signalling in white adipose tissue was impaired ${ }^{(42)}$. In line with the previous reports, the findings of the present study suggest that chitooligosaccharide-mediated inhibition of adipogenesis involved increased PTGS2 gene expression, which is linked to a proinflammatory response.

While the present study does not explore the interactions between IL-6 and PTGS2, it can be hypothesised that the elevated concentrations of IL- 6 may influence the expression of the PTGS2 gene. While $I L-6$ expression was dependent on the concentration of chito-oligosaccharide and expressed at the lowest levels, the PTGS2 expression was only elevated at the higher chito-oligosaccharide concentrations. The promoter region of the PTGS2 gene has two binding sites for CCAAT/enhancer-binding protein- $\beta$ (CEBP $\beta$, also known as NF-IL-6) ${ }^{(43)}$. The CEBP $\beta$ transcription factor complex is an IL-6-dependent DNA-binding protein, hence one could expect its transcriptional activity level to increase with increased intracellular abundance of IL-6. In support of this concept, two CEBP $\beta$ sites present in the promoter region of the PTGS2 gene were important for the higher expression of the PTGS2 gene in activated murine mast cell $34^{(43)}$.

Among the genes whose expression was down-regulated due to the chito-oligosaccharide treatment included many genes involved in the lipid biosynthesis process. The downregulation of the PPAR $\gamma$ gene has also been reported to be mediated through the action of $\mathrm{PGE}_{2}$, since the latter had an inhibitory role on the expression of $P P A R \gamma^{(44)}$. PPAR $\gamma$ is a (a)

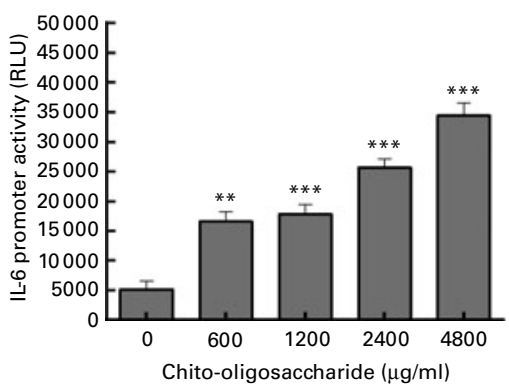

(b)

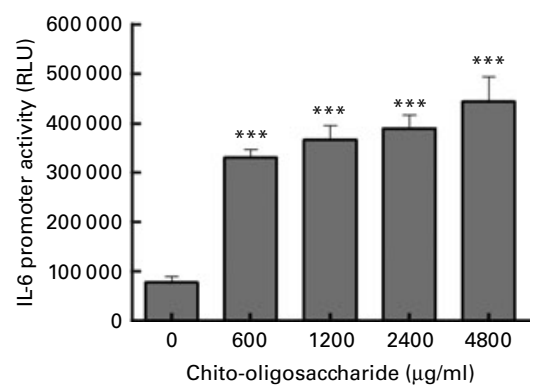

Fig. 6. Effects of chito-oligosaccharide on IL-6 promoter activity; expressed as relative luciferase units (RLU). Mouse 3T3-L1 pre-adipocytes were transiently transfected with the human IL-6 gene promoter construct and treated with chito-oligosaccharide (molecular weight 5-10 000 Da) in (a) serum-free medium or (b) serumcontaining differentiation medium. Values are means from three independent replications, with standard errors represented by vertical bars. Mean values were significantly different in comparison with the chito-oligosaccharide control $(0 \mu \mathrm{g} / \mathrm{ml})$ group: ${ }^{\star \star} P<0.01,{ }^{\star \star \star} P<0 \cdot 001$. 


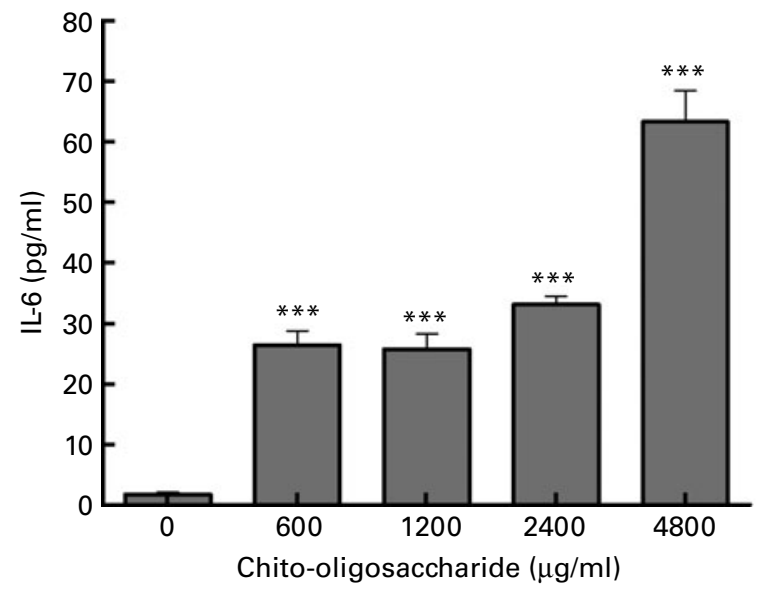

Fig. 7. Effects of chito-oligosaccharide on the secretion of IL-6 protein during adipogenesis. Mouse 3T3-L1 pre-adipocytes were induced to differentiate in the presence of chito-oligosaccharide (molecular weight 5-10000 Da). At day 8 of induction of adipogenesis, IL-6 protein in the cell culture medium was quantified using ELISA. Values are means from three independent replications, with standard errors represented by vertical bars. Mean values are significantly different in comparison with the chito-oligosaccharide control $(0 \mu \mathrm{g} / \mathrm{ml})$ group: ${ }^{* \star *} P<0 \cdot 001$.

potent transcription factor, which is a major activator of the differentiation process that ultimately leads to lipid accumulation in adipocytes ${ }^{(45)}$. Our data support a previous report on the inhibition of PPAR $y$ expression at protein and mRNA levels by chito-oligosaccharides ${ }^{(3)}$. A reduction in the expression of FABP4 and FABP5 genes indicated that chitooligosaccharide-mediated inhibition of adipogenesis may have occurred during the process of fatty acid uptake, transport and metabolism ${ }^{(46)}$. In adipocytes, the SCD is an important enzyme required for lipid metabolism ${ }^{(47)}$. It regulates the synthesis of SFA, and a dramatic reduction in the SCD gene expression due to the chito-oligosaccharide treatment indicated a reduction in the synthesis of $\mathrm{SFA}^{(47)}$.

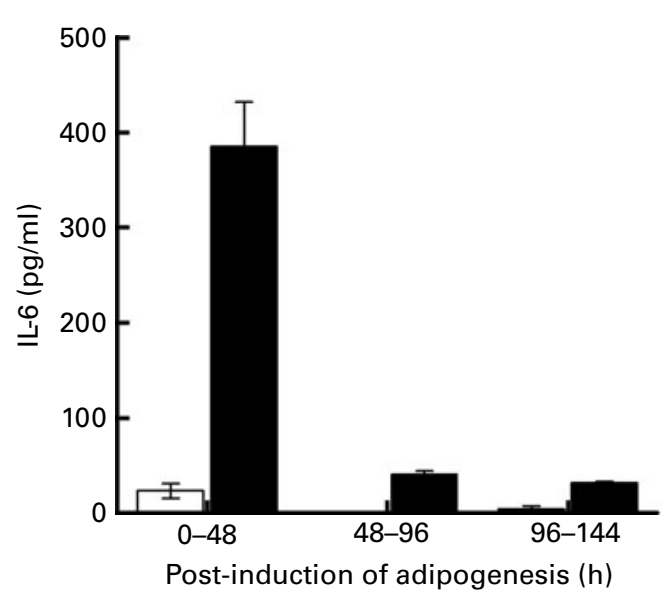

Fig. 8. Temporal effects of chito-oligosaccharide treatment $(0 \mu \mathrm{g} / \mathrm{ml}(\square)$ and $2400 \mu \mathrm{g} / \mathrm{ml}(\boldsymbol{\square}))$ on the secretion of IL-6 protein during adipogenesis. Mouse 3T3-L1 pre-adipocytes were induced to differentiate in the presence of chito-oligosaccharide (molecular weight 5-10000 Da). The cell lysate was harvested at 48,96 and $144 \mathrm{~h}$ post-induction of adipogenesis and IL- 6 protein was quantified using ELISA. Values are means from three independent replications, with standard errors represented by vertical bars.
Surprisingly, the genes whose expression was downregulated were conspicuous only when a high concentration of chito-oligosaccharides $(4800 \mu \mathrm{g} / \mathrm{ml})$ was used. Although the cell viability and cytotoxicity data indicate that chito-oligosaccharide at $4800 \mu \mathrm{g} / \mathrm{ml}$ after $48 \mathrm{~h}$ of incubation may affect cell health adversely, for the adipogenesis study, it is unlikely that the down-regulation of the genes was a manifestation of the cytotoxicity effect of chito-oligosaccharide. This is primarily because the chito-oligosaccharides in the serum-containing medium used during adipogenesis would likely to have only minimal effect on the cell health compared with the serumfree medium used for the cell viability and cytotoxicity tests ${ }^{(48,49)}$. Second, during the adipogenesis process, fresh medium was introduced in every alternate day, which is likely to further minimise the cytotoxic effect due to nutrient depletion in the medium. Third, most of the marker genes of the PCR array had established their roles in the lipid metabolism process and their alteration in expression level was as expected. The exact physiological concentration of chitooligosaccharide, which can be attainable in human subjects without adverse health effect, is presently unknown, although it is suggested that toxic side effects have not yet been reported in human subjects after oral administration of a dose as high as $3 \mathrm{~g} / \mathrm{d}^{(50)}$. Similarly, no side effects have been reported in mice after oral administration of a dose of $200-600 \mathrm{mg} / \mathrm{kg}$ per $\mathrm{d}^{(50,51)}$.

In conclusion, we have identified that IL-6, and PTGS2 to a lesser extent, are among the vital signalling molecules in the chito-oligosaccharide-mediated inhibition of adipogenesis in the 3T3-L1 cells. The IL-6 produced by chito-oligosaccharide can cause a breakdown of lipid molecules as well as the prevention of lipid accumulation during adipogenesis, while the high level of PTGS2 gene expression may contribute to the PG-mediated inhibition of the differentiation of pre-adipocytes to adipocytes. Since chito-oligosaccharide has the potential to regulate the expression of $I L-6$ and PTGS2 genes that may inhibit adipogenesis, further in vivo and in vitro studies would be useful to explore its potential use as a functional food to reduce adipogenesis in human subjects.

\section{Acknowledgements}

The present study was funded jointly by the Department of Agriculture, Food and Fisheries, Ireland and Marine Institute under the Marine Functional Food Research Initiatives (NutraMara consortium). The authors would like to thank Dr Sam Maher and Dr Jason McMorrow of the Veterinary Sciences Centre for their technical assistance in the cell viability and cytotoxicity experiments and promoter assay experiments, respectively. B. B. contributed to the study design and laboratory work, T. S. contributed to the study design and data collection and J. V. O. D. contributed to the data analysis. All the authors contributed to the writing of the manuscript and interpretation of the results, reviewing its content and approved the final version submitted for publication. None of the authors had a financial or personal conflict of interest in relation to the present study. 


\section{References}

1. Low SC, Chin MC \& Deurenberg YM (2009) Review on epidemic of obesity. Ann Acad Med Singapore 38, 57-59.

2. Kumar MNVR (2000) A review of chitin and chitosan applications. React Funct Polym 46, 1-27.

3. Cho EJ, Rahman A, Kim SW, et al. (2008) Chitosan oligosaccharides inhibit adipogenesis in 3T3-L1 adipocytes. J Microbiol Biotechnol 18, 80-87.

4. Rinaudo M (2006) Chitin and chitosan: properties and applications. Prog Polym Sci 31, 603-632.

5. Kean T \& Thanou M (2010) Biodegradation, biodistribution and toxicity of chitosan. Adv Drug Deliv Rev 62, 3-11.

6. Chandy T \& Sharma CP (1990) Chitosan - as a biomaterial. Biomater Artif Cells Artif Organs 18, 1-24.

7. Thanou M, Verhoef JC \& Junginger HE (2001) Chitosan and its derivatives as intestinal absorption enhancers. Adv Drug Deliv Rev 50, S91-S101.

8. Chae SY, Jang MK \& Nah JW (2005) Influence of molecular weight on oral absorption of water soluble chitosans. J Control Release 102, 383-394.

9. Fernandes JC, Tavaria FK, Soares JC, et al. (2008) Antimicrobial effects of chitosans and chitooligosaccharides, upon Staphylococcus aureus and Escherichia coli, in food model systems. Food Microbiol 25, 922-928.

10. Kaats GR, Michalek JE \& Preuss HG (2006) Evaluating efficacy of a chitosan product using a double-blinded, placebo-controlled protocol. J Am Coll Nutr 25, 389-394.

11. Preuss HG \& Kaats GR (2006) Chitosan as a dietary supplement for weight loss: a review. Curr Nutr Food Sci 2, 297-311.

12. Zeng L, Qin C, Wang W, et al. (2008) Absorption and distribution of chitosan in mice after oral administration. Carbohydr Polym 71, 435-440.

13. Mourya VK \& Inamdar NN (2008) Chitosan - modifications and applications: opportunities galore. React Funct Polym 68, 1013-1051.

14. Kim SK \& Rajapakse N (2005) Enzymatic production and biological activities of chitosan oligosaccharides (COS): a review. Carbohydr Polym 62, 357-368.

15. Jin L, Yumin D \& Hongbo L (2006) Low molecular weight water-soluble chitosans: preparation with the aid of cellulase, characterization, and solubility. Food Chem 102, 1098-1105.

16. Vinsova J \& Vavrikova E (2008) Recent advances in drugs and prodrugs design of chitosan. Curr Pharm Des 14, 1311-1326.

17. Green H \& Kehinde O (1975) An established preadipose cell line and its differentiation in culture II. Factors affecting the adipose conversion. Cell 5, 19-27.

18. Gregoire FM, Smas CM \& Sul HS (1998) Understanding adipocyte differentiation. Physiol Rev 78, 783-809.

19. Prokesch A, Hackl H, Hakim WR, et al. (2009) Novel insights into adipogenesis from omics data. Curr Med Chem 16, 2952-2964.

20. Ntambi JM \& Young CK (2000) Adipocyte differentiation and gene expression. J Nutr 130, 3122S-3126S

21. Voshol PJ, Rensen PCN, van Dijk KW, et al. (2009) Effect of plasma triglyceride metabolism on lipid storage in adipose tissue: studies using genetically engineered mouse models. Biochim Biophys Acta 1791, 479-485.

22. Kumar SG, Rahman MA, Lee SH, et al. (2009) Plasma proteome analysis for anti-obesity and anti-diabetic potentials of chitosan oligosaccharides in ob/ob mice. Proteomics $\mathbf{9}$, 2149-2162.

23. Hoene M \& Weigert C (2008) The role of interleukin-6 in insulin resistance, body fat distribution and energy balance. Obes Rev 9, 20-29.
24. Hirai S, Takahashi N, Goto T, et al. (2010) Functional food targeting the regulation of obesity-induced inflammatory responses and pathologies. Mediators Inflamm 2010, 367838.

25. Hansen JB, Petersen RK, Larsen BM, et al. (1999) Activation of peroxisome proliferator-activated receptor $\gamma$ bypasses the function of the retinoblastoma protein in adipocyte differentiation. J Biol Chem 274, 2386-2393.

26. Otto W, Taylor TG \& York DA (1976) Glycerol release in vitro from adipose tissue of obese $(\mathrm{ob} / \mathrm{ob})$ mice treated with thyroid hormones. $J$ Endocrinol 71, 143-155.

27. Stinshoff K, Weisshaar D, Staehler F, et al. (1977) Relation between concentrations of free glycerol and triglycerides in human sera. Clin Chem 23, 1029-1032.

28. Livak KJ \& Schmittgen TD (2001) Analysis of relative gene expression data using real-time quantitative PCR and the 2-[delta][delta]CT method. Methods 25, 402-408.

29. Bahar B, O'Halloran F, Callanan M, et al. (2011) Bovine lactoferrin $(L T F)$ gene promoter haplotypes have different basal transcriptional activities. Anim Genet (Epublication ahead of print version 6 February 2011).

30. Rahman A, Kumar SG, Kim SW, et al. (2008) Proteomic analysis for inhibitory effect of chitosan oligosaccharides on 3T3-L1 adipocyte differentiation. Proteomics $\mathbf{8}, 569-581$.

31. Wallenius V, Wallenius K, Ahrén B, et al. (2002) Interleukin6-deficient mice develop mature-onset obesity. Nat Med $\mathbf{8}$, $75-79$.

32. Kamimura D, Ishihara K \& Hirano T (2003) IL6 signal transduction and its physiological roles: the signal orchestration model. Rev Physiol Biochem Pharmacol 149, 1-38.

33. van Hall G, Steensberg A, Sacchetti M, et al. (2003) Interleukin-6 stimulates lipolysis and fat oxidation in humans. J Clin Endocrinol Metab 88, 3005-3010.

34. Gustafson B \& Smith U (2006) Cytokines promote wnt signaling and inflammation and impair the normal differentiation and lipid accumulation in 3T3-L1 preadipocytes. J Biol Chem 281, 9507-9516.

35. Qin C, Du Y, Xiao L, et al. (2002) Enzymic preparation of water-soluble chitosan and their antitumor activity. Int J Biol Macromol 31, 111-117.

36. Fasshauer M, Kralisch S, Klier M, et al. (2003) Adiponectin gene expression and secretion is inhibited by interleukin-6 in 3T3-L1 adipocytes. Biochem Biophys Res Comm 301, $1045-1050$.

37. Moon HS, Lee HG, Seo JH, et al. (2008) Lipolysis is stimulated by PEGylated conjugated linoleic acid through the cyclic adenosine monophosphate-independent signaling pathway in 3T3-L1 cells: activation of MEK/ERK MAPK signaling pathway and hyper-secretion of adipo-cytokines. J Cell Physiol 214, 283-294.

38. Harris SG, Padilla J, Koumas L, et al. (2002) Prostaglandins as modulators of immunity. Trends Immunol 23, 144-150.

39. Hyman BT, Stoll LL \& Spector AA (1982) Prostaglandin production by 3T3-L1 cells in culture. Biochim Biophys Acta 713, 375-385.

40. Tsuboi H, Sugimoto Y, Kainoh T, et al. (2004) Prostanoid EP4 receptor is involved in suppression of 3T3-L1 adipocyte differentiation. Biochem Biophys Res Commun 322, 1066-1072.

41. Hetu PO \& Riendeau D (2007) Down-regulation of microsomal prostaglandin E2 synthase-1 in adipose tissue by high-fat feeding. Obesity 15, 60-68.

42. Fain JN, Madan AK, Hiler ML, et al. (2004) Comparison of the release of adipokines by adipose tissue, adipose tissue matrix, and adipocytes from visceral and subcutaneous abdominal adipose tissues of obese humans. Endocrinology 145, 2273-2282. 
43. Reddy ST, Wadleigh DJ \& Herschman HR (2000) Transcriptional regulation of the cyclooxygenase-2 gene in activated mast cells. J Biol Chem 275, 3107-3113.

44. Reginato MJ, Krakow SL, Bailey ST, et al. (1998) Prostaglandins promote and block adipogenesis through opposing effects on peroxisome proliferator-activated receptor $\gamma . J$ Biol Chem 273, 1855-1858.

45. Berger JP (2005) Role of PPARy, transcriptional cofactors, and adiponectin in the regulation of nutrient metabolism, adipogenesis and insulin action: view from the chair. Int J Obes Relat Metab Disord 29, S3-S4.

46. Maeda K, Cao H, Kono K, et al. (2005) Adipocyte/ macrophage fatty acid binding proteins control integrated metabolic responses in obesity and diabetes. Cell Metab $\mathbf{1}$, 107-119.
47. Jones BH, Standridge MK, Claycombe KJ, et al. (1998) Glucose induces expression of stearoyl-CoA desaturase in 3T3-L1 adipocytes. Biochem J 335, 405.

48. Seibert H, Mörchel S \& Gülden M (2002) Factors influencing nominal effective concentrations of chemical compounds invitro: medium protein concentration. Toxicol In Vitro 16, 289-297.

49. Gülden M, Mörchel S \& Seibert H (2003) Serum albumin binding at cytotoxic concentrations of chemicals as determined with a cell proliferation assay. Toxicol Lett 137, 159-168.

50. Sumiyoshi M \& Kimura Y (2006) Low molecular weight chitosan inhibits obesity induced by feeding a high-fat diet long-term in mice. J Pharm Pharmacol 58, 201-207.

51. Rahman MA, Kumar SG \& Yun JW (2010) Proteome analysis in adipose tissue of ob/ob mice in response to chitosan oligosaccharides treatment. Biotechnol Bioprocess Eng 15, 559-571. 